\title{
EDITORIAL
}

\section{Epidemiological psychiatry}

Epidemiology in the broad sense is no more the preserve of epidemiologists than statistics of professional statisticians. Both as a method of investigation and as the body of knowledge acquired thereby, it now finds application in all clinical specialties, including psychiatry. As the use of representative samples and of adequate control groups becomes more usual in psychiatric research, while at the same time routine administrative statistics gain in scope and accuracy, the need for a distinct subspeciality of 'epidemiological psychiatry' should dwindle and disappear; but this happy consummation, like the withering-away of the Marxist state, remains as yet a distant prospect.

The epidemiological method, so far from being unique, is shared with sociologists, social psychologists, and other non-medical workers who engage in survey research; only his exclusive preoccupation with illness as the dependent variable serves to distinguish the epidemiologist (Mechanic, 1970). Professional demarcation lines are especially difficult to draw in the study of behavioural disorders, where the definition of 'illness' is least precise: today's dependent variable may achieve independence tomorrow as medical, legal, and social concepts change. Thus, alcoholism, drug abuse, delinquency, and suicide may be regarded as subjects either for medical or for social investigation.

Epidemiology as an observational and descriptive science stands in that Hippocratic tradition of study of the 'natural history' of disease which has been renewed periodically throughout the history of medicine (Greenwood, 1935). As an analytical science, however, it is characterized by three essentially modern concepts-namely, the population denominator, interaction between illness determinants, and the exponential spread of diseases in communities (Stewart, 1970). Each developed first in infectious epidemiology, but has since been extended to the study of non-infectious disease and of crowd behaviour. In psychiatry, the most influential so far has been the idea of the denominatoraccording to Stewart '. . . about as important in medical thinking as the invention of the wheel, and equally revolutionary'-but with the advent of computer technology, both multivariate analysis of determinants and the construction of mathematical models of disease inception and spread have become feasible.

The basic aims of epidemiology are to estimate rates of inception and prevalence in populations, and to test for differences between the rates for defined subgroups. To achieve these aims, a series of steps must be undertaken, comprising the choice of an appropriate research strategy; definition of the population at risk and, where required, selection of a representative sample; formulation of a clear case-definition; identification of all cases by means of a valid diagnostic technique; and expression of the findings in terms of standard morbidity indices. Problems of method may be encountered at each of these stages. In particular, case-identification in modern urban societies demands a complex procedure, in which the administration of mass screening techniques (Eastwood, 1971) is followed by more intensive examination of suspected cases (Goldberg, Cooper, Eastwood, Kedward, and Shepherd, 1970).

The scope of epidemiology in modern psychiatry covers the planning of mental health services, the enlargement of clinical perspectives, and the search for causal factors; numerous examples can be drawn from each of these areas (Cooper and Morgan, 1973). The value of survey statistics is now widely recognized by medical administrators who, in order to assess the service needs of a population, must have information about the prevalence, distribution, and severity of illness and handicap among its members. Equally vital for planning is a knowledge of the ways in which both morbidity patterns and the utilization of medical services are changing. Recently, a third function has gained prominence: that of the evaluation of psychiatric services (Wing and Hailey, 1972).

Involvement in this sphere is not without its dangers for the research worker. Understandably 
eager that his findings and recommendations should be given duc weight in the planning process, he fully accepts the need for what Black (1972) has called 'an effective interface' between science and government; on the other hand, he sets great store by his freedom to pursuc chosen topics without regard to their immediate application, or to the vagaries of political fashion. Somewhere a compromise has to be struck between scientific independence and public responsibility. In this situation the epidemiologist, like other medical investigators, can derive great benefit from the support and guidance of his clinical colleagues.

Unfortunately, the need for population-based studies is still insufficiently appreciated by many clinical psychiatrists; chiefly, no doubt, because of their concentration on the individual patient. It should be remembered that epidemiology is directly relevant to clinical practice, in two ways. First, any physician may use the methods of clinical epidemiology to trace the origin and mode of transmission of disease among his patients: an approach exemplified in psychiatry by Alarcón's study of heroin abuse in an English town (Alarcón, 1969). Secondly, clinical diagnosis and prognosis rely ultimately on actuarial data, since each constitutes a statement of certain probabilities regarding the aetiology, pathology, course and outcome of illness, and its response to treatment. Thus, the field of child psychiatric disorder is open to reappraisal in the light of recent survey findings (Rutter, Tizard, and Whitmore, 1970; Shepherd, Oppenheim, and Mitchell, 1971). Perhaps the most telling example, however, is a negative one: the absence of any recourse to population studies throughout the long, sterile controversy over the classification of depressive illness. Clinical thinking at its best is constantly alert to the wider perspectives of community diagnosis.

The delineation of high-risk groups, whether as a basis for service provision or as a guide to individual prognosis, is also the logical first step in the search for causes. Observed variations in the frequency of any disorder may point to associations between its inception rate and various biological, psychological, and social indices which then demand further scrutiny. The achievements of epidemiologists in the field of infectious aetiology are widely known. More recently, applications of the same principles to the study of non-infectious disease has yielded some impressive results (British Medical Bulletin, 1971), although here investigators are being forced more and more to postulate multifactorial causation and to resign themselves to a painstaking assembly of the jigsaw-puzzle of disease.

In the early part of this century Adolf Meyer stressed the importance of the biographical life-chart for an understanding of individual psychopathology. Equally, study of the mass aspects of mental disorder must comprehend risk-factors operating at any time from conception to the onset of illness and beyond. Such factors may be grouped for convenience into those concomitant with the established illness, those which operate immediately beforehand (precipitating factors), and those present over long periods or at an earlier phase of the life-span (predisposing factors). Most attention has been given to those in the first group, simply because of their accessibility in 'cross-sectional' surveys. For the most part, however, investigation of crude demographic characteristics has proved unrewarding and the problems of establishing cause-and-effect relationships by this approach intractable. Potentially more fruitful are studies in which a firm chronological relationship between event and illness can be demonstrated.

Remarkably little empirical research has been undertaken into the precipitation of mental illness, despite-or perhaps because of-much confusion in the notions of 'reactivity' held by different schools of psychiatry. From the epidemiological standpoint, a single criterion is sufficient-namely, a positive statistical association between the inception rate of a disease and the occurrence of some defined environmental change (Cooper and Shepherd, 1970). Recent studies of events preceding acute schizophrenic and depressive illness, besides fulfilling this criterion, have provided some evidence on the nature of the causal link (Brown, Harris, and Peto, 1973).

Paradoxically, in explaining part of the variation in illness-rates, studies of precipitating factors have served to underline the importance of predisposition. The individual's expectation of psychiatric disorder is influenced by his genetic inheritance, his environment in utero, and the biological and sociocultural risk-factors to which he is exposed in early life; epidemiological surveys have 
supplied some of the leading evidence on each of these points (Milbank Memorial Fund, 1961).

Of recent years, there has been a growing awareness of the need for more sophisticated techniques. Current research subsumes a wide range of methodological studies, of which the development of valid, reliable screening tests (Goldberg, 1972), the standardization of diagnostic interviews (Wing, Birley, Cooper, Graham, and Isalacs, 1967; Goldberg et al., 1970), the use of multiaxial classifications (Rutter, Lebovici, Eisenberg, Sneznevskij, Sadoun, Brooke, and Lin, 1969; Wing, 1970), and the construction of measures of family activities and relationships (Brown and Rutter, 1966) are notable examples. As a result, the quality of survey data can be expected to improve steadily over the next decade.

Apart from improvements in technique, survey investigations will be influenced by changes in the spectrum of morbidity; by closer coordination with other disciplines; and by a growing emphasis on preventive measures in psychiatry.

As patterns of community morbidity continue to evolve, some major public health concerns of our day will decline in relative importance, while others such as senile degenerative disorders, drug abuse, self-poisoning, and 'stress disorders' come to the forefront. Superimposed on this process of change will be the results of modern methods of treatment and medical care; so that, for example, the prevalence of chronic institutionalism and 'social breakdown syndrome' (Gruenberg, 1969) is likely to diminish. All such changes will inevitably be reflected in national research priorities.

Some convergence of epidemiological research on mental and on physical illness is to be anticipated as areas of common interest become more clearly defined (Eastwood and Trevelyan, 1972). At the same time, survey methods will be more frequently incorporated into clinical and experimental programmes in psychiatry, as in the study of physical habitus (Little and Kerr, 1968) and of abnormal karyotypes (Brown, Buckton, Jacobs, Tough, Kuenssberg, and Knox, 1966).

Finally, epidemiology may be expected to gain in recognition as the scientific basis of preventive psychiatry. The hazards of an approach to prevention lacking such a basis are already apparent in. current trends towards long-term chemical prophylaxis (Lancet, 1972). Given the present limitations of knowledge, any realistic programme for prevention is bound to concentrate on the secondary and tertiary stages - that is to say, on the early diagnosis and treatment of established illness and the reduction of chronic handicaps. It may be, indeed, that over the next 10 or 20 years operational and evaluative studies of services will afford the greatest opportunities for progress.

So far, gains in the primary prevention of mental disorders have emerged chiefly as by-products of advances in general medicine and surgery: the eradication of epidemic diseases; the introduction of antibiotics; improved standards of obstetric care. On the world scene, there can be little doubt that general health measures continue to offer the best hope for reducing psychiatric morbidity. In developed industrial countries, however, there is increasing scope for more direct intervention, if only because technological advance and mounting population pressures are bringing into operation new environmental risk-factors which must be identified and controlled. Topical examples include the effects of aircraft noise and of high-density housing; the mental health problems of immigrant workers; psychiatric aspects of oral contraception and large-scale abortion; the possible dangers of atmospheric lead pollution; and the genetic consequences of increased levels of radioactivity.

In the pursuit of these and similar lines of inquiry, medical investigators must be prepared when necessary, as public health epidemiologists have always been prepared, to come to grips with political and social issues; not as a substitute for, but as an essential part of, their scientific vocation.

BRIAN COOPER

\section{REFERENCES}

Alarcón, R., de (1969). The spread of heroin abuse in a community. Bulletin on Narcotics, 21, No. 3, 17-22.

Black, D. A. K. (1971). A note on R. \& D. Lancet, 2, 870.

British Medicul Bulletin (1971). Epidemiology of noncommunicable disease. 27, No. 1. British Council: L.ondon.
Brown, W. M. Court, Buckton, K. E., Jacobs, P. A., Tough, I. M., Kuenssberg, E. V., and Knox, J. D. E. (1966). Chromosome studies on adults. Eligenics Laboratory Memoirs, No. 42. Published for the Galton Laboratory London by Cambridge University Press: London. 
Brown, G. W., Harris, T. O., and Peto, J. (1973). Life events and psychiatric disorders. Part 2: Nature of causal link. Psychological Medicine, 3, 159.176.

Brown, G. W., and Rutter, M. (1966). The measurement of family activities and relationships. A methodological study. Human Relations, 19, 241-263.

Cooper, B., and Morgan, H. G. (1973). Epidemiological Psychiarry. Thomas: Springfield, Ill.

Cooper, B., and Shepherd, M. (1970). Life change, stress and mental disorder: the ecological approach. In Modern Trends in Psychological Medicine 2, pp. 102-130. Edited by J. H. Price. Butterworths: London.

Eastwood, M. R. (1971). Screening for psychiatric disorder. Psychological Medicine, 1, 197-208.

Eastwood, M. R., and Trevelyan, M. H. (1972). The relationship between physical and psychiatric disorder. Psychological Medicine. 2, 363-372.

Goldberg, D. P. (1972). The identification of psychiatric illness by questionnaire. Maudsley Monograph No. 21. Oxford University Press: London.

Goldberg, D. P., Cooper, B., Eastwood, M. R., Kedward, H. B., and Shepherd, M. (1970). A standardized psychiatric interview for use in community surveys. British Journal of Preventive and Social Medicine, 24, 18-23.

Greenwood, M. (1935). Epidemics and Crowd-Diseases. Williams and Norgate: London.

Gruenberg, E. M. (1969). From practice to theory. Community mental-health services and the nature of psychoses. Lancet, 1, 721-724.

Lancet (1972). Management of a depressive illness (editorial). 2, 864-865.

Little, J. C., and Kerr, T. A. (1968). Some differences between published norms and data from matehed controls as a basis for comparison with psychologically-disturbed groups. British Jourmal of Psirhiarry, 114, 88.3-890.

Mechanic, D. (1970). Problems and prospects in psychiatric epidemiology. In Psychiorric Episl'miolegy', pp. 3-22. Edited by E. H. Hare, and J. K. Wing. Oxford University Press: London, for Nufficld Provincial Hospitals Trust:

Milbank Memorial Fund (1961). Canses of Memal Disurders: a review of epidemiological kmowledge, pp. 19-59. Milbank Memorial Fund: New York.

Rutter, M., Tizard, J., and Whitmorc, K. (editor). (1970). Education, Healhh and Behaviour. Longmans: Harlow.

Rutter, M., Lebovici, S., Eisenberg, L., Sneznevskij, A. V., Sadoun, R., Brooke, E., and Lin, T.-Y. (1969): A tri-axial classification of mental disorders in childhood. An international study. Journal of Child Psychology and Psychiotry, $10,41-61$.

Shepherd, M., Oppenheim, B., and Mitchell, S. (1971). Childhood Behaviour and Memlal Health. University of London Press: London.

Stewart, G. T. (1970). Epidemiological approach to assessment of health. Lancet, 2, 115-119.

Wing, J. K., Birley, J. L. T., Cooper, J. E., Graham, P., and Isaacs, A. D. (1967). Reliability of a procedure for measuring and classifying 'present psychiatric state'. British Journal of Psychiatry, 113, 499-515.

Wing, J. K., and Hajley, A. M. (editors). (1972). Evaluating a Community Psychiatric Service. The Camberwell Register, 1964-71. Oxford University Press: London for Nuffield Provincial Hospitals Trust.

Wing, L. (1970). Observations on the psychiatric section of the International Classification of Diseases and the British Glossary of Mental Disorders. Psychological Medicine, 1, 79-85. 